\title{
Integrating Daylighting with Task-Ambient Lighting for Enhanced Energy Savings in Office Spaces
}

\author{
Simeon Nyambaka Ingabo*, Pipat Chaiwiwatworakul \\ The Joint Graduate School of Energy and Environment, King Mongkut's University of Technology \\ Thonburi, Bangkok 10140 Thailand. \\ *Corresponding author: ingabosimeon@gmail.com
}

\author{
Article History \\ Received: May 18, 2021 \\ Received in revised form: July 04, 2021 Accepted: July 10, 2021 \\ Published Online: December 25, 2021
}

\begin{abstract}
Daylighting has been widely studied as a fundamental aspect of spatial illumination and energy efficient façade design. Effective installation and control of shading devices diminishes the adverse effects of prevailing climatic conditions on building envelope performance and reduces resultant lighting and cooling energy consumption. Task-ambient lighting as a free-standing approach has also been proven to reduce lighting energy consumption compared with typical general ambient lighting. This study estimates the energy saving potential of integrating daylighting through fixed external horizontal shading slats with task lighting. Spot measurements were taken in a test room to validate a daylight calculation program. Full year indoor work plane daylight simulations were performed for office spaces of different floor areas and varying window to wall ratios. Indoor daylight quality was assessed using the Useful Daylight Illuminance metric and three different task lighting schemes explored. Lighting energy savings of $10 \%$ to $90 \%$ were estimated under the three schemes in comparison to similar office spaces with common unshaded heat reflective glazing.
\end{abstract}

Keywords: Daylighting; Task-Ambient Lighting; External Slats; Daylight Distribution; Energy Savings.

\subsection{INTRODUCTION}

Electric lighting alongside heating or cooling are the principal drivers of energy consumption in office buildings [1,2]. Several authors have explored the utilization of daylight to significantly reduce energy consumption by electric lamps in commercial buildings [3-5]. However, daylight has to be effectively controlled to guarantee a satisfactory indoor environment for the occupants [6]. Shading devices are a prevalent feature of building facades in daylight-abundant geographical locations such as the tropics and they have been applied for lighting and cooling energy consumption reduction $[7,8]$ as well as enhancement of indoor thermal and visual comfort $[9,10]$. A variety of shading devices exists and they can be broadly categorized into external and internal shading devices. The selection of an appropriate configuration is dependent on factors such as climate type, geographical location, aesthetic considerations, material properties, among others.

External shading slats are simple, inexpensive and low maintenance devices. They perform better than internal slats in terms of overall energy consumption as noted by Atzeri et al. [11] who compared the effect of both configurations on lighting and cooling energy demand in office buildings in Italy. The authors observed that while both configurations had a similar effect on lighting energy demand, external slats reduced cooling energy demand whereas an increase was evident with internal shading slats. The impact of external shading slats on indoor daylight distribution was analyzed by Alzoubi and Al-Zoubi [12] and compared with unshaded windows. A simulation study of an office building in Jordan with south-facing windows was performed using Lightscape software. Fixed external slats were incorporated and it was observed that at an optimum tilt angle, the shading device achieved comfortable illuminance levels and recommended spatial visual quality.

Integrating several lighting approaches also improves energy savings as established by Tzempelikos and Athienitis [13]. Daylighting with automated motorized shading was blended with controllable electric lighting, resulting in lighting energy consumption reduction of up to $77 \%$. Tagliabue et. al [1] rendered three office spaces using several simulation programs and integrated natural daylight with artificial lighting under dimmable control and on/off control achieving significant energy savings in each case. It was noted that occupants desire to control their immediate visual environment 
despite the availability of advanced automated building control models. Kralikova et al. [14] discussed combining daylighting with zonal lighting in factory buildings with each zone representing a different stage of the production process with different illuminance requirements. This approach in its basic form may not be suitable for office spaces since office tasks are generally similar in nature.

Task lighting allows for the localized control of electric lighting based on the illuminance requirements of each occupant's specific tasks in a workspace. Veitch et al. [15] conducted a lighting appraisal in an open plan office with nine workstations. Six lighting configurations were considered including switchable desk lamps and luminaires with independent workstation dimming. It was observed that better task visibility and lighting conditions resulted in better task performance. It was also established that office occupants with individual control of their lighting conditions were more motivated and satisfied with their tasks. Another related study by Newsham et al. [16] examined occupants' satisfaction under two lighting designs. One design had only ceiling luminaires for ambient lighting while the second had both ceiling luminaires and angle-arm task lighting. Task lighting improved task performance but only reduced ambient lighting energy consumption by roughly the same energy consumed by the task lighting lamps.

Jones and Gordon [17] compared several lighting schemes including a task-ambient lighting scheme with mechanical switching to a reference case of common office lighting with an array of lamps that provided typical uniform illuminance on all surfaces. The study found energy savings of $22 \%$ and recommended the adoption of task-ambient lighting due to its low cost and ease with which it can be fused into existing infrastructure. However, these studies did not incorporate daylighting in their lighting designs which could further decrease ambient lighting energy consumption.

Most authors approach the analysis of daylighting performance of shading devices in terms of both lighting and cooling or heating energy consumption due to the inherent interdependence between daylight and associated solar radiation. However, this paper focuses solely on lighting energy consumption. It examines the effect of fixed external horizontal shading slats on indoor daylight quality and distribution at workstations in office buildings of different geometric dimensions and window to wall ratios. It also seeks to estimate the lighting energy savings from integrating daylighting with task-ambient lighting under three dissimilar schemes. Both experimental and simulation methods were adopted using spot measurements in a physical test room and a validated daylight calculation program respectively.

\subsection{METHODOLOGY}

\section{1}

\section{Experiments}

Daylight measurements were taken in a stand-alone full-scale test room to represent an ordinary office space in Thailand. The room was located at King Mongkut's University of Technology Thonburi's Bang Khun Thien campus in Bangkok, Thailand $\left(13.7^{\circ} \mathrm{N}, 100.4^{\circ} \mathrm{E}\right)$. It had white colored external horizontal shading slats as shown in Figure. 1 (a) and (b). A previous study at the same location determined that similar slat configurations installed on south facing windows and tilted downwards at an angle of $30^{\circ}$ completely shaded unwanted beam solar radiation and daylight throughout the year [10], thus the slats used in this study were fixed at $30^{\circ}$ all year round. The room had a width $\mathrm{W}=3 \mathrm{~m}, \mathrm{depth} \mathrm{D}=9 \mathrm{~m}$ and floor to ceiling height $\mathrm{H}=2.65 \mathrm{~m}$. A $1.8 \mathrm{~m}$ high window installed at a height of $0.85 \mathrm{~m}$ above the floor characterized the south-facing façade of the test room. The slats installed on the window had an inter-slat separation distance of $0.1 \mathrm{~m}$ and slat width of $0.13 \mathrm{~m}$. Surface and material properties are outlined in Table 1 . The indoor environment was conditioned by a fan coil unit.

Lux meters were installed inside the test room at a work plane height of $0.85 \mathrm{~m}$ along the center of the room to measure work plane illuminance at 10\% room depth (0.1D), 30\% (0.3D), 50\% (0.5D), 70\% (0.7D) and 90\% (0.9D). An additional lux meter was installed in close proximity to the glazed window to measure transmitted illuminance. Figure 2 shows a cross-sectional illustration of the experimental set up. Twenty-four-hour minute-by-minute indoor illuminance measurements were recorded by a data logger on two different days in April and December. Corresponding outdoor global, diffuse and beam horizontal daylight illuminance measurements were simultaneously recorded by a meteorological station located at the same site. Outdoor global, diffuse and beam vertical daylight illuminance measurements in the four cardinal orientations were also recorded by the weather station.

\subsection{Simulations}

\subsubsection{Simulation Program}

Daylight illuminance measurements from the experiments were used to validate a simulation program called BESim which has been used by several researchers for daylight and building energy simulation [10,18-21]. BESim's algorithm, architecture and daylight and heat transfer calculation procedures are described in Chaiwiwatworakul et. al [19] and Hien and Chirarattananon [22]. The validated program was used to perform annual daylight calculations using full year daylight records obtained from the meteorological station. 


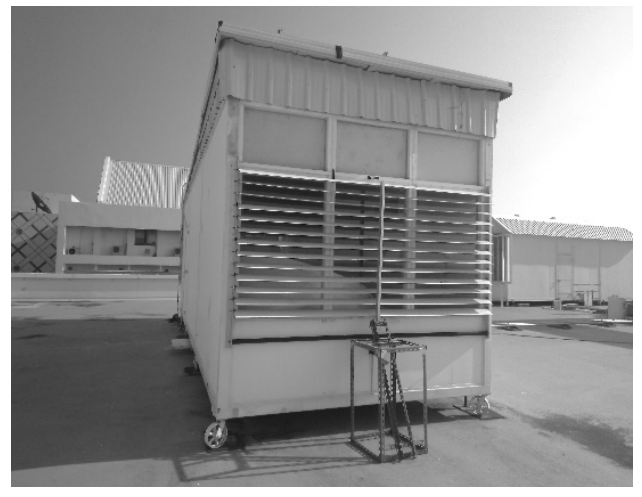

(a) Exterior view

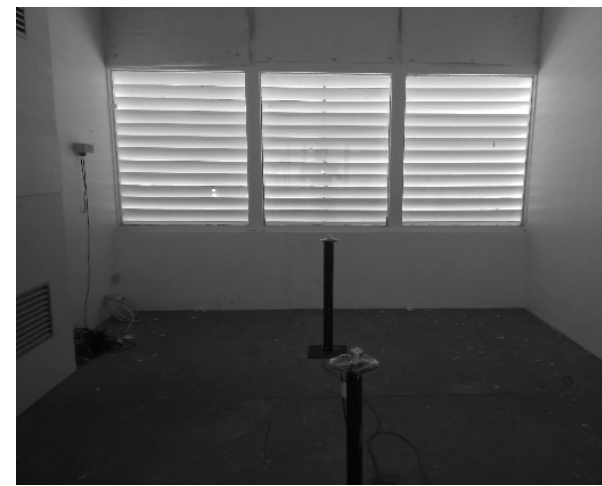

(b) Interior view

Figure 1: Exterior and interior view of the test room.

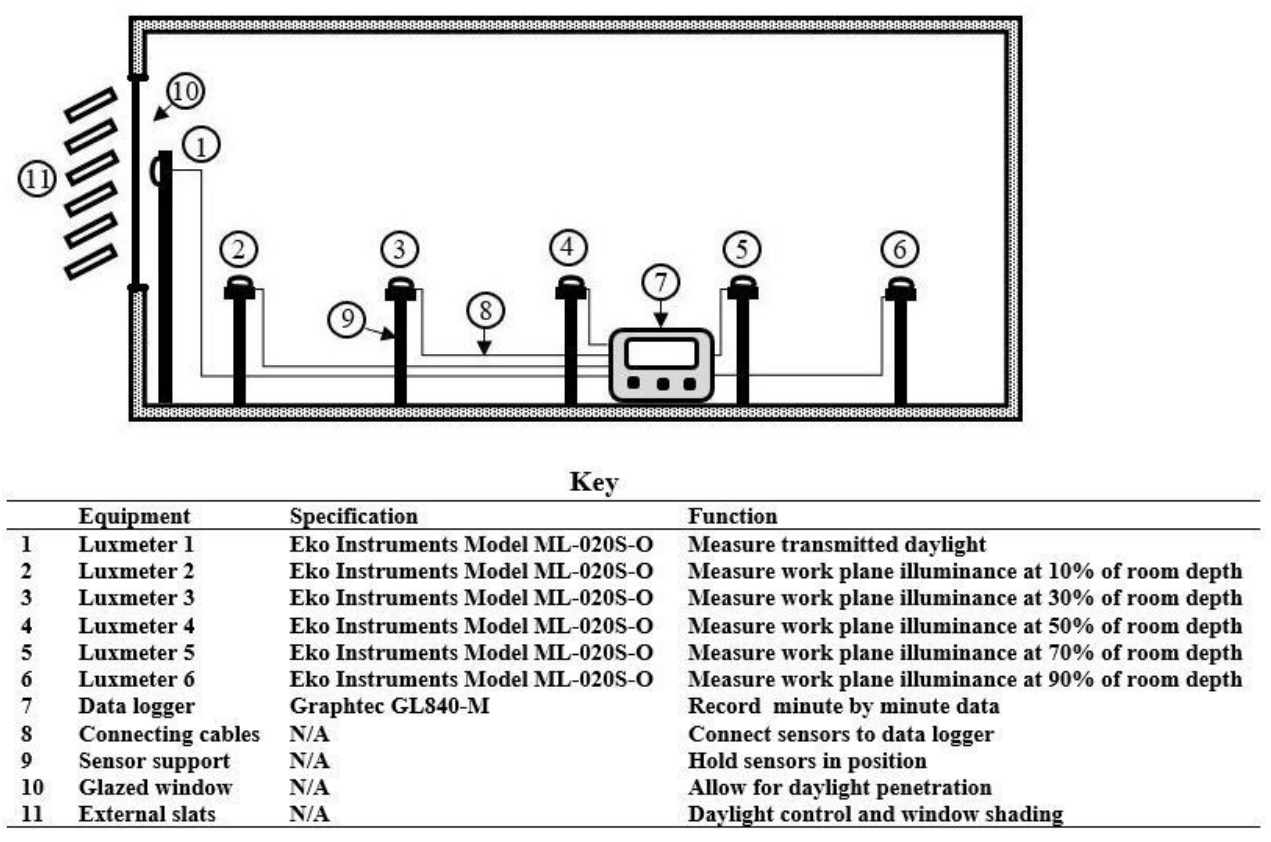

Figure 2: Cross sectional illustration of experimental set up.

Table 1: Surface and material properties

\begin{tabular}{|l|c|c|c|c|}
\hline & Clear glass & Heat reflective glass & Slat & Opaque wall \\
\hline Material & Glass & Glass & Aluminum & Lightweight concrete \\
\hline Thickness (m) & 0.006 & 0.012 & 0.002 & 0.1 \\
\hline Visible transmittance & 0.88 & 0.09 & 0.0 & 0.0 \\
\hline Visible reflectance & 0.08 & 0.32 & 0.8 & 0.5 \\
\hline Solar transmittance & 0.8 & 0.06 & 0.0 & 0.0 \\
\hline Solar reflectance & 0.07 & 0.33 & 0.8 & 0.5 \\
\hline
\end{tabular}

\subsubsection{Office Spaces}

Five office spaces of floor to ceiling height $\mathrm{H}=2.65 \mathrm{~m}$ and varying width and depth were selected for simulation. The office spaces were assumed to be part of an office building in Thailand and surface and material properties were similar to the test room. Three spaces were square shaped with different floor areas as shown in Table 2. Two rectangular shaped office spaces with different width and depth but equal floor area were selected to examine the effect of variations in room dimensions on energy consumption per unit floor area. Each office space was divided into five zones extending inwards from the shaded window and measuring 0.2D each as shown in Figure. 3. Work stations were distributed uniformly within 
each office space based on the recommendation of $10 \mathrm{~m}^{2}$ for each occupant as demarcated by the dotted lines in Fig. 3 . Zonal locations of each work station are indicated in Table 2. Illuminance measurement points were assumed to be centrally located in each zone. Window to wall ratios (WWR) of 0.3, 0.6 and 0.9 were considered for each workspace. Simulations were performed for cases when the windows had clear glass with external horizontal shading slats similar to those installed on the test room. Reference simulations were also performed for similar room configurations with heat reflective glass windows commonly preferred for conventional office building designs in Thailand.

Table 2: Office space configurations

\begin{tabular}{|c|c|c|c|c|c|c|c|}
\hline$W \times D$ & Floor Area $\left.\mathbf{( m}^{\mathbf{2}}\right)$ & No. Work stations & Zone A & Zone B & Zone C & Zone D & Zone E \\
\hline $3 \times 3$ & 9 & 1 & 0 & 0 & 1 & 0 & 0 \\
\hline $3 \times 9$ & 27 & 3 & 1 & 0 & 1 & 0 & 1 \\
\hline $9 \times 3$ & 27 & 3 & 0 & 0 & 3 & 0 & 0 \\
\hline $9 \times 9$ & 81 & 8 & 2 & 2 & 0 & 2 & 2 \\
\hline $15 \times 15$ & 225 & 23 & 5 & 4 & 5 & 4 & 5 \\
\hline
\end{tabular}

\subsubsection{Lighting Schemes}

Three lighting schemes were examined based on illuminance requirements recommended by the Illumination Engineering Society of North America (IESNA) [23]. In the first scheme (scheme 1), a target work plane illuminance of 500lux was adopted as recommended for office tasks. It was assumed that dimmable LED lamps were installed uniformly on the ceilings of the selected rooms for ambient lighting. The properties of the lamps are shown in Table 3. The IESNA lumen method illustrated by Eq. 1 was used to calculate lighting power density (LPD).

$$
E_{w}=(L L F)(C U)(L f / P)(P / A)
$$

Where : $E_{w}$ is target workplace illuminance (lux)

$L L F$ is the light loss factor $(0.8)$

$C U$ is the coefficient of utilization $(0.65)$

$L f / P$ is the efficacy $(\mathrm{lm} / \mathrm{W})$

$P / A$ is the lighting power density $\left(\mathrm{W} / \mathrm{m}^{2}\right)$

Lighting energy consumption by the ceiling lamps was computed by multiplication of average lighting power densities (LPD) at the five work plane illuminance measurement points by floor area and total annual working hours.

In the second scheme (scheme 2), the target work plane illuminance was lowered to 300lux for ambient lighting by the ceiling lamps. Lighting energy consumption by the ceiling lamps was calculated using the same method as in scheme 1 with the target work plane illuminance set at 300lux. Each work station was also equipped with a task lighting desk lamp with properties shown in Table 3 to ensure that the recommended office task illuminance requirement of 500lux was still met on the desks. In this scheme the desk lamps were assumed to be ON throughout working hours. Task lighting energy consumption was calculated as a product of the energy consumption by each desk lamp, total number of lamps and working hours during the work year.

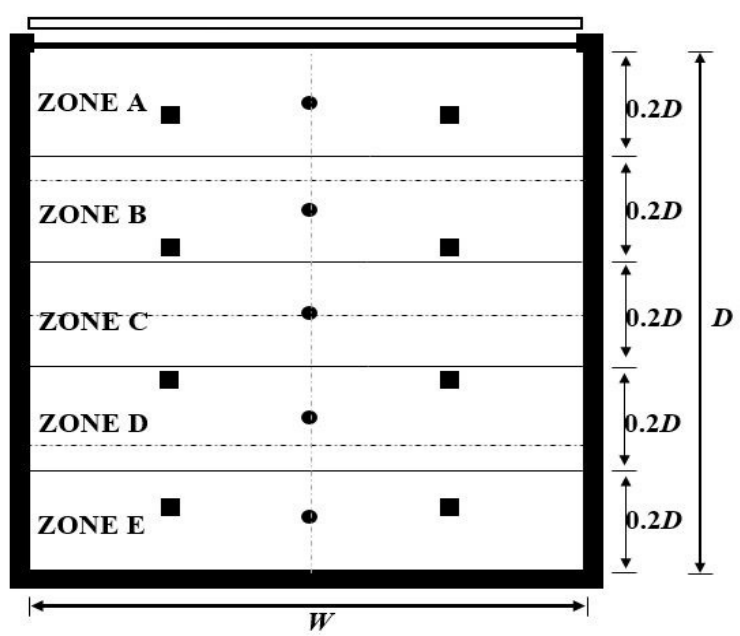

Workstation •Illuminance measurement point

Figure 3: Aerial illustration of zonal workstation distribution in a $9 \times 9$ office space. 
The third scheme (scheme 3) was similar to scheme 2 but the desk lamps were assumed to have an ON/OFF mechanism to turn the lamps ON when work plane illuminance on the desks fell below 500lux and OFF when illuminance exceeded 500lux. The total number of working hours during the work year when work plane illuminance fell below 500lux was determined and total lighting energy consumption determined using a similar approach as in scheme 2. A lighting approach whereby the ceiling lamps were fully ON during working hours was adopted for the reference cases with heat reflective glass, a common practice in office buildings.

Table 3: Lighting specifications.

\begin{tabular}{|l|l|l|l|l|}
\hline \multicolumn{3}{|c|}{ Ceiling luminaires } & \multicolumn{2}{c|}{ Desk lamps } \\
\hline Target illuminance (lux) & 500 & 300 & Description & LED daylight-white (6500 Kelvin) \\
\hline Number of lamps per luminaire & 2 & 2 & Light flux $(\mathrm{lm})$ & 460 \\
\hline Total light flux $(\mathrm{lm})$ & 5360 & 5360 & Range of adjustable height $(\mathrm{m})$ & $0.25-0.62$ \\
\hline Total power $(\mathrm{W})$ & 58.9 & 58.9 & Illuminance at $0.25 \mathrm{~m}(\mathrm{lux})$ & 2000 \\
\hline Efficacy $(\mathrm{lm} / \mathrm{W})$ & 90.9 & 90.9 & Energy efficiency class & A \\
\hline Lighting power density $\left(\mathrm{W} / \mathrm{m}^{2}\right)$ & 10.58 & 6.35 & Total power $(\mathrm{W})$ & 10 \\
\hline
\end{tabular}

\subsection{RESULTS AND DISCUSSION}

\subsection{Experiments}

Two separate experiments were conducted in the test room on different days with the slats fixed at $30^{\circ}$. The first experiment was performed in April. At this time of the year, the sun was overhead at this particular location and migrating northwards. Figure 4(a) shows the outdoor daylight measurements. On this day the sky was predominantly clear with a dominant beam normal component $E v b$. Diffuse horizontal daylight $E v d$ contributed roughly a third of total global horizontal daylight $E v g$. The fixed external shading slats intercepted as much as half of the total global vertical daylight incident on the southern façade $E v S$. Figure 4(b) shows the indoor work plane illuminance measurements taken in the test room plotted alongside corresponding simulation results. Work plane illuminance Evi at $0.1 D$ and $0.3 D$ exceeded 500lux during working hours. At $0.5 D, 500$ lux was achieved between 11:00 and 14:00 but fell below during morning and evening periods. At 0.7D and 0.9D work plane illuminance was below 500lux throughout the day.

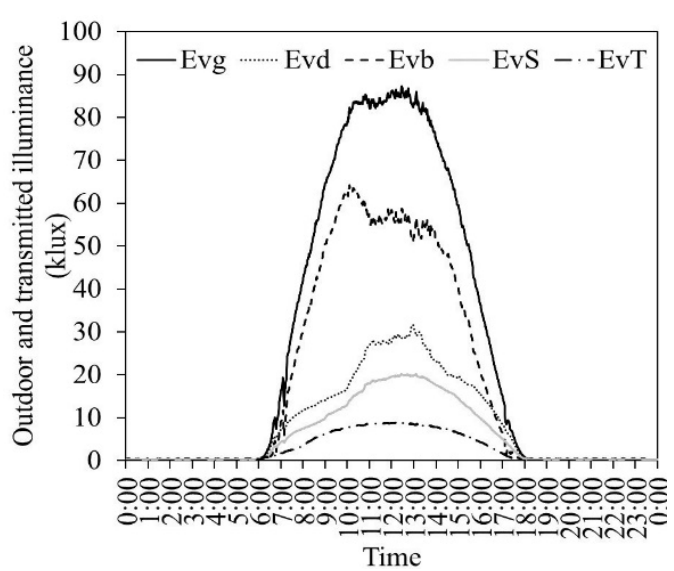

(a) Outdoor illuminance

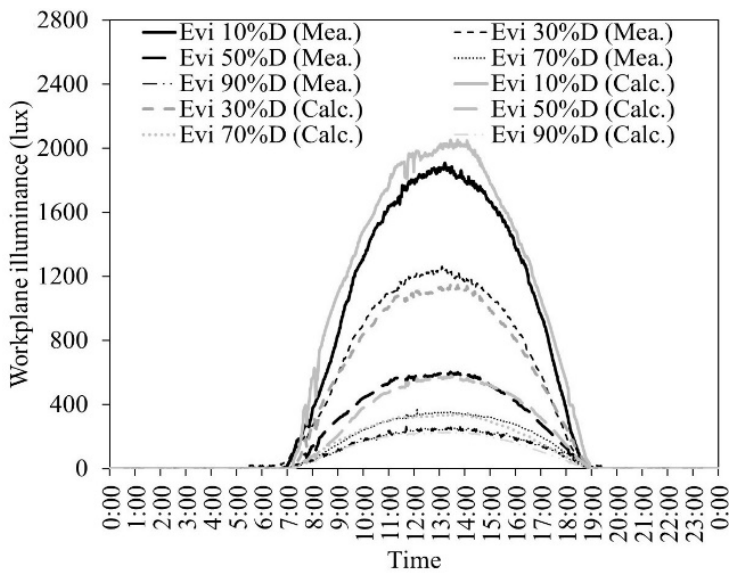

(b) Indoor illuminance

Figure 4: Outdoor and indoor illuminance for the experiment in April.

Another experiment was performed in the test room in December. At this time of the year the sun appeared in front of the shaded window thus incident illuminance on the south facing façade $E v S$ was higher than in the first experiment as shown in Figure 5(a). On this day the sky was intermittently cloudy with highly variant daylight between 12:00 and 14:00. The shading slats intercepted as much as $80 \%$ of total incident daylight as indicated by transmitted daylight EvT. Work plane illuminance also exceeded 500lux during working hours at $0.1 D, 0.3 D$ and $0.5 D$ as in the first experiment. 


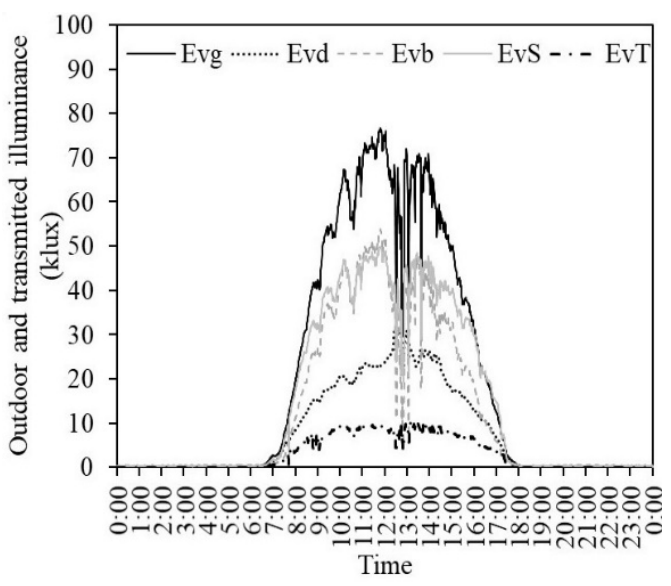

(a) Outdoor illuminance

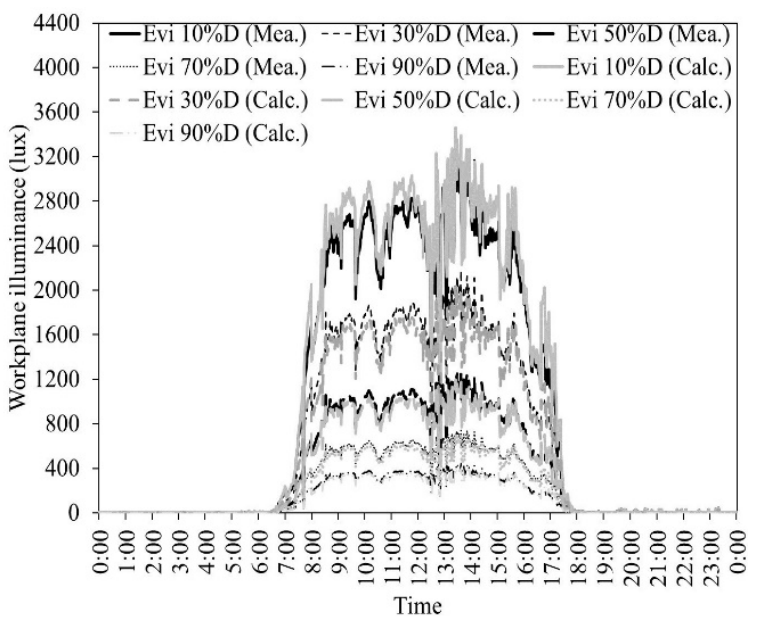

(b) Indoor illuminance

Figure 5: Outdoor and indoor illuminance for the experiment in December.

Measurement and simulation results were compared using the mean bias error $M B E$ and root mean square error RMSE indicators calculated using Eq.2 and Eq.3 respectively.

$$
\begin{aligned}
& M B E=\frac{1}{N} \sum_{i=1}^{N}\left(C_{i}-M_{i}\right) \\
& R M S E=\sqrt{\frac{1}{N} \sum_{i=1}^{N}\left(C_{i}-M_{i}\right)^{2}}
\end{aligned}
$$

where $C_{i}$ is the calculated value, $M_{i}$ is the corresponding measured experimental value, and $N$ is the number of data points considered. Measured and simulation values were consistent but in both cases the simulation program slightly underestimated the work plane illuminance at $0.3 D, 0.5 D, 0.7 D$ and $0.9 D$ as evidenced by Figure 6 . Overestimation at $0.1 D$ was higher than at other points but its impact on the study was insignificant since 500lux was always achieved at this point throughout the day due to its close proximity to the window.

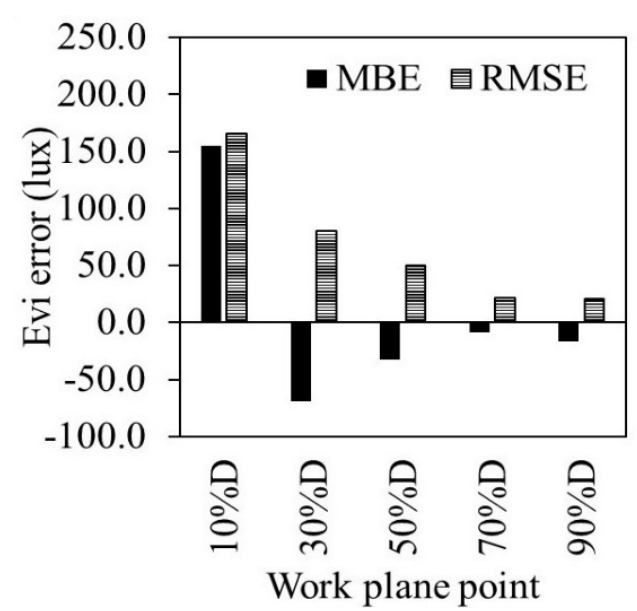

(a) Experiment in April

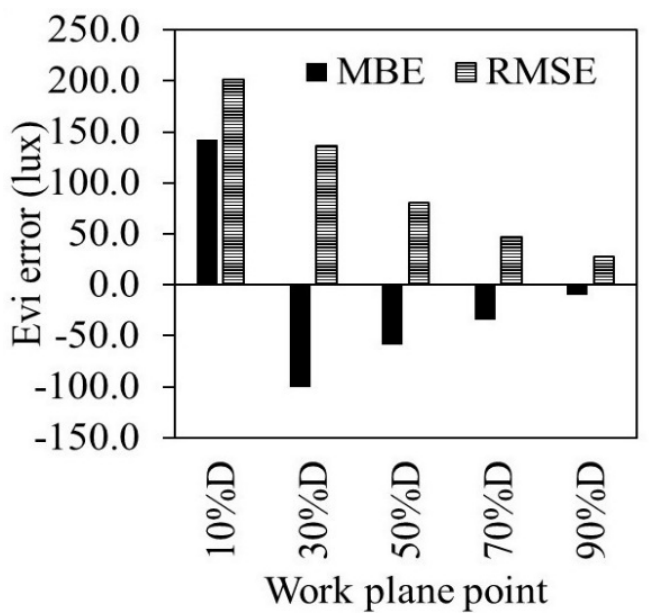

(b) Experiment in December

Figure 6: MBE and RMSE of measured and calculated data.

\subsection{Simulations}

The validated BESim program was used to perform full year simulations of work plane illuminance for the office spaces described in section 2.2.2. 


\subsubsection{Daylight Availability}

Annual weather records from the meteorological station indicate an abundance of daylight during working hours at the study location throughout the year as shown in Figure 7. Outdoor global horizontal illuminance was as high as $125 \mathrm{klux}$ with an annual average of 55klux. Incident daylight on the southern façade was also high averaging $25 \mathrm{klux}$ over the course of the work year.

The quality of indoor daylight was assessed using the Useful Daylight Illuminance metric UDI which corresponds to the percentage of the work year when work plane illuminance levels were between 100lux and 2000lux as proposed by Mardaljevic [24]. Illuminance levels within these limits were considered useful while those below were deemed insufficient and those above were deemed excessive and undesirable. Figure 8 shows the zonal distribution of daylight in the office spaces for different WWRs. For WWR $=0.3$, the window is characterized by a smaller aperture which consequently reduces the amount of daylight that penetrates into the interior of the workspace. The aperture and daylight penetration generally increased with increasing WWR. However, there was minimal difference between UDI levels for $\mathrm{WWR}=0.6$ and $\mathrm{WWR}=0.9$ since in the latter case the window sill was lower than the work plane level hence the additional daylight only had a slight effect on work plane illuminance. The $3 \times 3$ office space with external shading slats had a shallow depth and thus received ample useful daylight with UDI ranging from $60 \%-96 \%$ across the five zones in all office spaces examined. Despite the shallow depth, a $3 \times 3$ office space with HR glass and WWR $=0.3$ experienced higher UDI levels closer to the window in zones $\mathrm{A}, \mathrm{B}$ and $\mathrm{C}$ which decreased significantly as one moved away from the window in zones $\mathrm{D}$ and $\mathrm{E}$ as seen in Fig. 8(b). This can be attributed to the reduced visible transmittance of the HR glass which reduces solar radiation transmission but in turn also curtails daylight penetration and distribution.

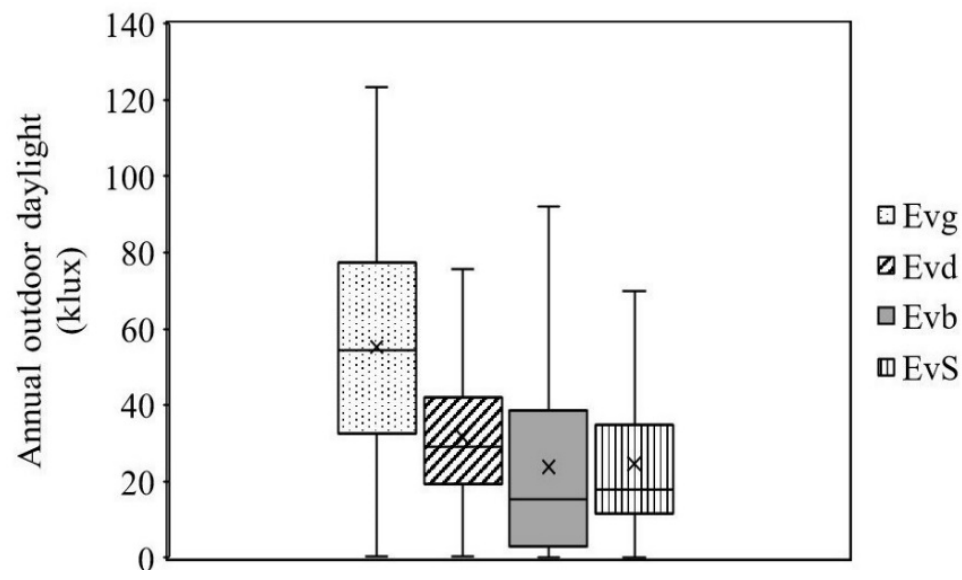

Figure 7: Annual outdoor daylight.

\subsubsection{Indoor Daylight Distribution And Quality}

For $W W R=0.6$ and $W W R=0.9$, the office spaces measuring $3 \times 3,9 \times 3$ and $9 \times 9$ and equipped with external slats achieved UDI over 50\% in all zones as observed in Fig. 8(c) and (e). It was also observed that more centrally located zones (zones $\mathrm{B}, \mathrm{C}$ and D) in these particular office spaces achieved UDI for longer periods compared to zone A which was closer to the window. This was due to zone A occasionally receiving illuminance levels exceeding the upper UDI limit of $20001 \mathrm{x}$. Despite having larger window sizes, office spaces measuring $15 \times 15$ performed poorly due to their greater depth and failed to achieve UDI at all in zones D and E when the windows had HR glass as seen in Fig. 8(b), (d) and (f). Increasing the WWR in this case had minimal impact on the daylight distribution in deeper zones.

The effect of variations in the shape of the office space in relation to width and depth were examined using the $9 \times 3$ and $3 \times 9$ office spaces which had the same floor area and number of workstations. The $9 \times 3$ office space achieved the best UDI levels among all office spaces examined for all WWRs and zones in both cases of external shading slats and HR glass. It had a shallow depth and greater width ensuring sufficient daylight penetration. The $3 \times 9$ office space had poor UDI performance since its narrow width and comparatively greater depth led to insufficient daylight penetration in the deeper zones. This was further aggravated by the HR glass where as many as four zones failed to achieve UDI at all as seen in Fig. 8b. It is therefore important to strike a proper balance between width and depth during design to achieve desirable daylight distribution and daylight quality. 


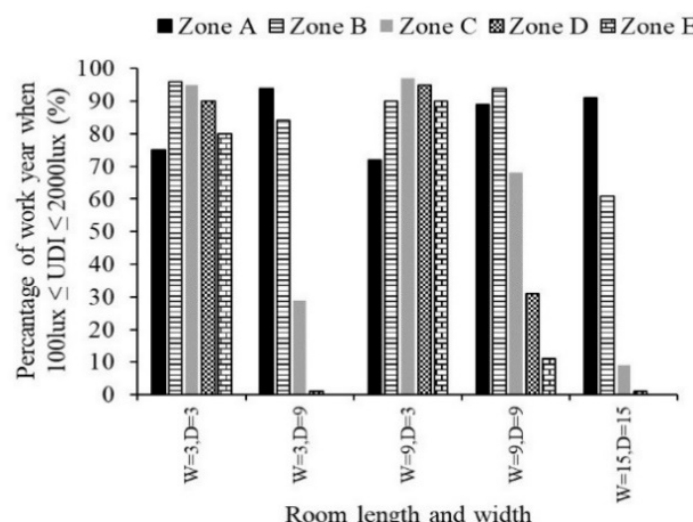

(a) Office spaces with external slats (WWR=0.3)

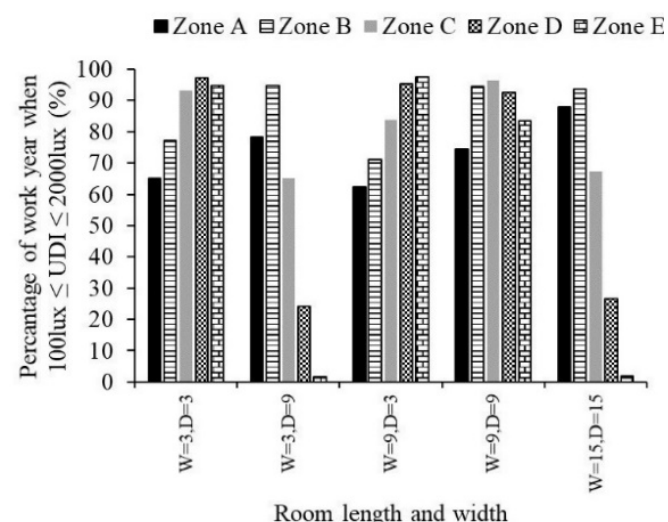

(c) Office spaces with external slats (WWR=0.6)

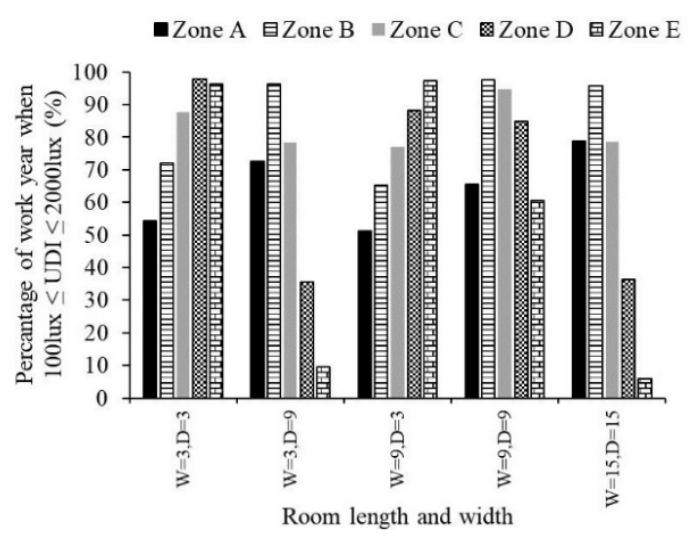

(e) Office spaces with external slats $(\mathrm{WWR}=0.9)$

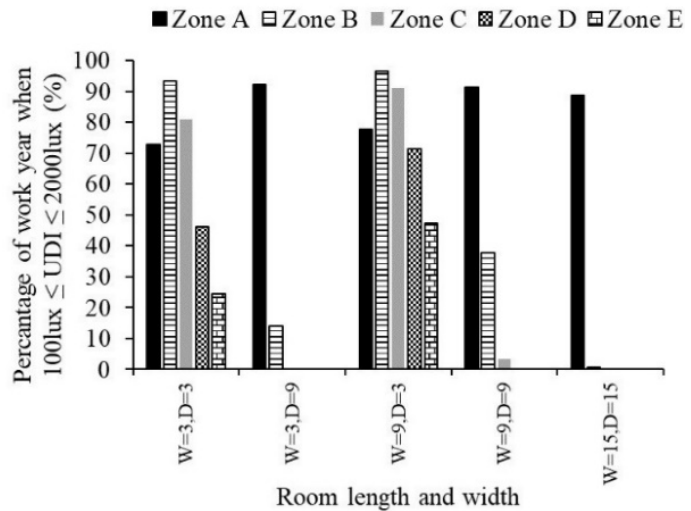

(b) Office spaces with HR glass (WWR=0.3)

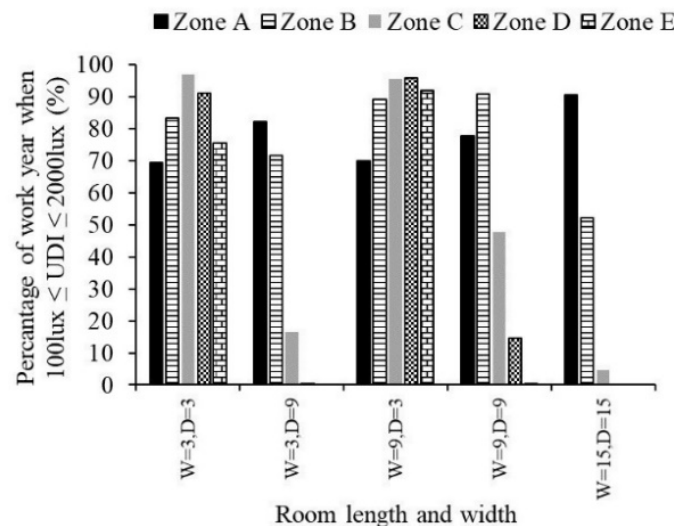

(d) Office spaces with HR glass (WWR=0.6)

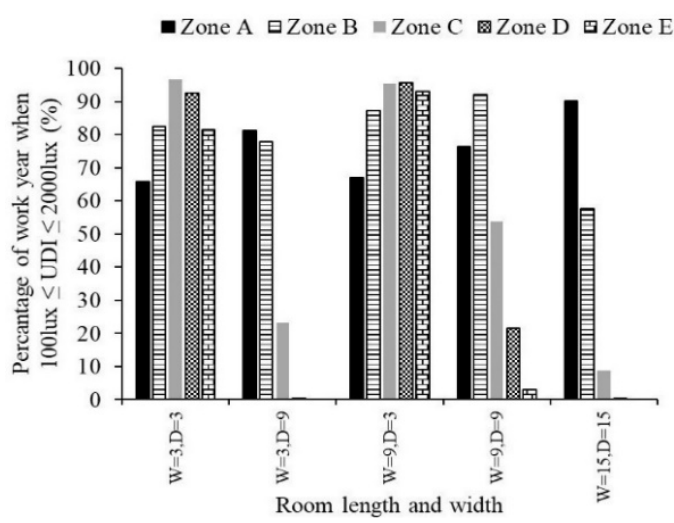

(f) Office spaces with HR glass (WWR=0.9)

Figure 8: Zonal UDI and daylight distribution

\subsubsection{Lighting Energy Consumption}

Annual daylight simulation results were used to calculate lighting energy as outlined in section 2.2.3. Figure 9 shows the annual lighting energy consumption per $\mathrm{m}^{2}$ of floor area. Daylight distribution directly influenced energy consumption and office spaces with better daylight quality in Fig 8 also consumed less energy as seen in Figure 9. As expected, lighting energy consumption was highest for $\mathrm{WWR}=0.3$ due to reduced daylight from the small window. Increasing the WWR to 0.6 reduced energy consumption by 3 to $6 \mathrm{kWh} / \mathrm{m}^{2}$. A further increase in WWR to 0.9 only yielded a further reduction of 0.5 to $2 \mathrm{kWh} / \mathrm{m}^{2}$. All office spaces with HR glass also consumed more lighting energy than the three schemes, roughly twice as much as schemes 2 and 3.

Scheme 1 in which a target illuminance of 500lux for general lighting was adopted resulted in twice as much energy consumption compared to schemes 2 and 3 except in office spaces measuring $3 \times 3$ and $9 \times 3$ with WWR=0.6 where daylight was sufficient and less artificial lighting was required. 


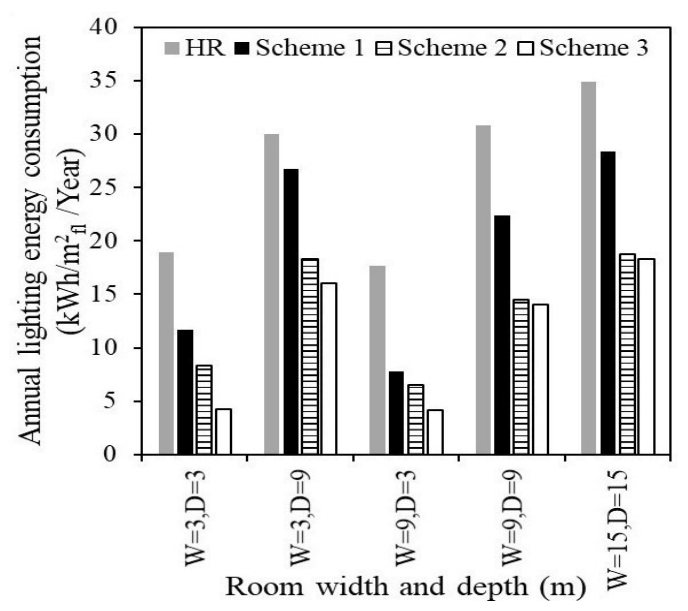

(a) $\mathrm{WWR}=0.3$

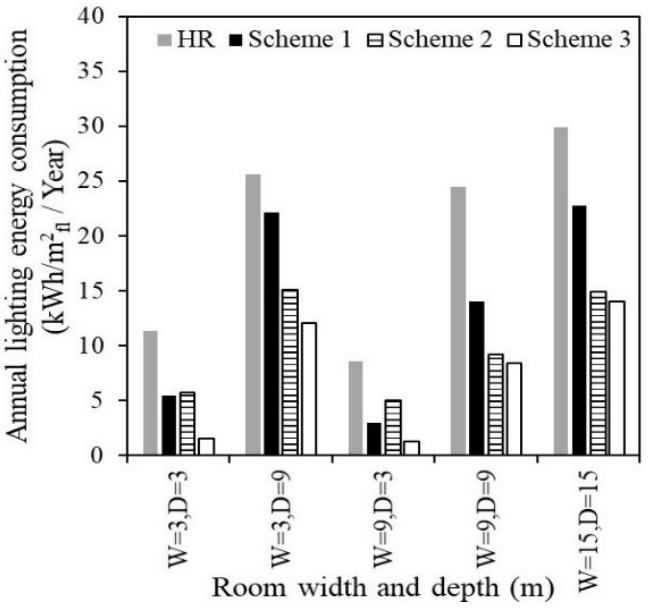

(b) WWR $=0.6$

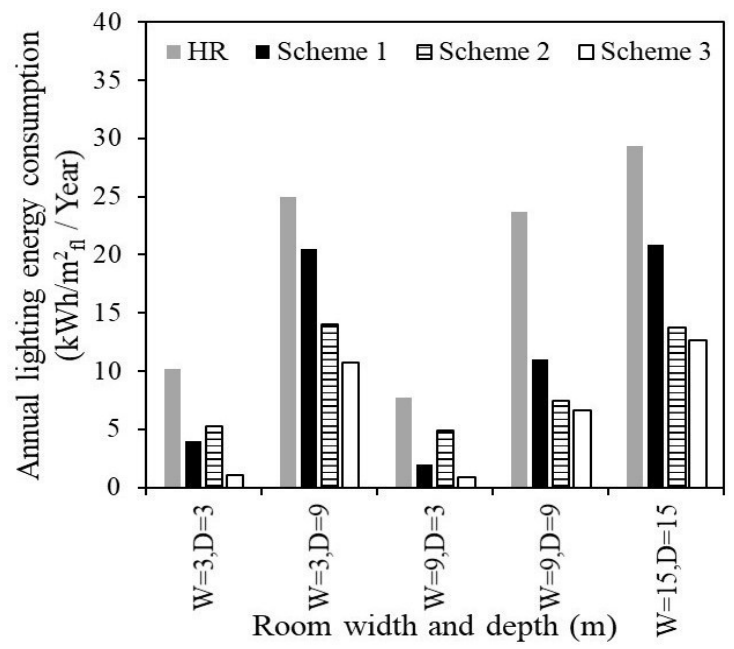

(c) $\mathrm{WWR}=0.9$

Figure 9: Annual lighting energy consumption.

Lowering the target illuminance to 300lux for general ambient lighting and only achieving the desired 500lux on top of the desks at the workstations by use of desk lamps presented an opportunity to further decrease lighting energy consumption since the ceiling lamps used for ambient lighting subsequently consumed less energy. In scheme 2, energy consumption was observed to be lower than scheme 1 for all office spaces with WWR $=0.3$. However, for $3 \times 3$ and $9 \times 3$ office spaces with $\mathrm{WWR}=0.6$ and $\mathrm{WWR}=0.9$, energy consumption was higher than in scheme 1 since the desk lamps were kept $\mathrm{ON}$ throughout working hours despite the abundance of daylight on the desks. Task lighting energy consumption by the desk lamps was the main component of total lighting energy consumption.

Scheme 3 remedied the task lighting energy consumption shortfalls of scheme 2 by only turning the desk lamps $\mathrm{ON}$ when daylight was insufficient. This further reduced energy consumption in shallow rooms with $\mathrm{D}=3 \mathrm{~m}$. However, there was little difference between energy consumption in the two schemes in deeper rooms with $D=9 \mathrm{~m}$ and $\mathrm{D}=15 \mathrm{~m}$ due to insufficient daylight penetration which reduced the number of hours when the desk lamps in scheme 3 were turned OFF. Scheme 2 may be favored especially in deeper workspaces due to its minimal interference with visual tasks compared to scheme 3 where the desk lamps are frequently turned ON and OFF and may irritate the occupants.

\subsubsection{Lighting Energy Savings}

Figure 10 shows the resultant energy savings from adoption of daylighting integrated with task-ambient lighting for south- 
oriented facades with external horizontal shading slats in comparison to conventional facades with heat reflective glass. Scheme 1 without task lighting saved $10 \%-30 \%$ of energy consumed per $\mathrm{m}^{2} \mathrm{fl}$. Introducing task lighting in schemes 2 and 3 increased energy savings to $37 \%-90 \%$ depending on the office space configuration. Scheme 3 registered the highest energy savings.

The effect of variations in WWR on energy savings is directly dependent on daylight distribution as discussed in section 3.2.2. It was observed that better daylight penetration yielded higher energy savings as witnessed in the shallow $3 \times 3$ and $9 \times 3$ workspaces. In these two offices spaces, increasing the WWR from 0.3 to 0.6 increased energy savings by $13 \%$ (scheme 1 ) and $10 \%$ (scheme 2 ) in the $3 \times 3$ office space and by $9 \%$ under both schemes in the $9 \times 3$ office space. In scheme 2 however, there was a decrease of $7 \%$ in the $3 \times 3$ office space and $22 \%$ in the $9 \times 3$ office space since the desk lamps in these schemes were kept ON during working hours despite daylight being sufficient most of the time. This implies that depending on the configuration of the office space, task-ambient lighting may not always yield energy savings. A similar observation was made when the WWR was increased from 0.6 to 0.9 with smaller increases in energy savings since additional daylight resulting from increased window aperture also improved the daylight distribution in cases with HR glass as shown in Figure 8 (d)-(f) but it was slightly more consequential with HR glass than external slats.

For the $3 \times 9$ and $9 \times 3$ office spaces with equal floor area but different width and depth, the largest difference in energy savings per $\mathrm{m}^{2} \mathrm{fl}$ between the two was observed in scheme 1 , with a difference of as much as $57 \%$ when $\mathrm{WWR}=0.9$. The small window aperture of the $3 \times 9$ office space due to its small width coupled with its relatively deeper depth ensured that energy savings remained low due to insufficient daylight penetration. This difference was greatly reduced with the adoption of schemes 2 and 3.

In the deep office spaces measuring $9 \times 9$ and $15 \times 15$, there were negligible differences between energy savings from schemes 2 and 3 since in both cases most of the workstations were located further from the window leading to insufficient daylight thus the desk lamps were ON throughout the working hours. Lighting energy savings estimated in this study were established to be driven by both office space configurations (WWR, width and depth) and lighting schemes.

\subsection{CONCLUSION}

This paper estimates the energy saving potential of combining daylighting with task-ambient lighting. Unlike conventional lighting designs which aim at maintaining an illuminance level of 500lux in office buildings using ceiling lamps regardless of specific individual tasks, task-ambient lighting offers an approach to ensure that the required illuminance is only achieved where it is required. Office space configurations such as window size, room width and room depth were key determinants of overall indoor daylight quality and resultant energy savings. Daylight control using external horizontal shading slats was established to be more beneficial especially for larger office spaces with great depths as the slats distribute daylight better than heat reflective glass. Integrating daylighting with task-ambient lighting further enhances the energy saving performance achieved using shading slats and significantly reduces energy consumption in office spaces.

Three schemes were examined and they yielded between $10 \%$ and $90 \%$ energy savings. The first scheme did not incorporate task lighting and thus resulted in the least energy savings. The second scheme was an improvement of the first scheme and included desk lamps that were kept ON throughout the working hours to maintain illuminance on the desk surfaces at 500lux while the ceiling lamps provided general ambient lighting at 300lux. This scheme had the second highest energy savings. The third scheme was an improvement of the second scheme and the desk lamps were only turned ON when illuminance on the desk surface was below 500lux. This scheme was the most energy efficient of the three. However, with constant innovations being witnessed in lighting technology, the third scheme could be improved further using dimmable and more efficient desk lamps and substituting fixed slats with adjustable slats.

Despite these promising energy-centric findings, additional research is recommended to determine occupants' visual, psychological and other non-energy oriented responses to different task-ambient lighting schemes in order to establish their applicability in actual working environments. A concurrent study examining both lighting and cooling energy consumption would also provide a more robust outline of the impact of variations in office space properties such as WWR on overall energy consumption. These findings are also limited to south oriented facades at this particular study location and may significantly differ from other façade orientations and locations. 


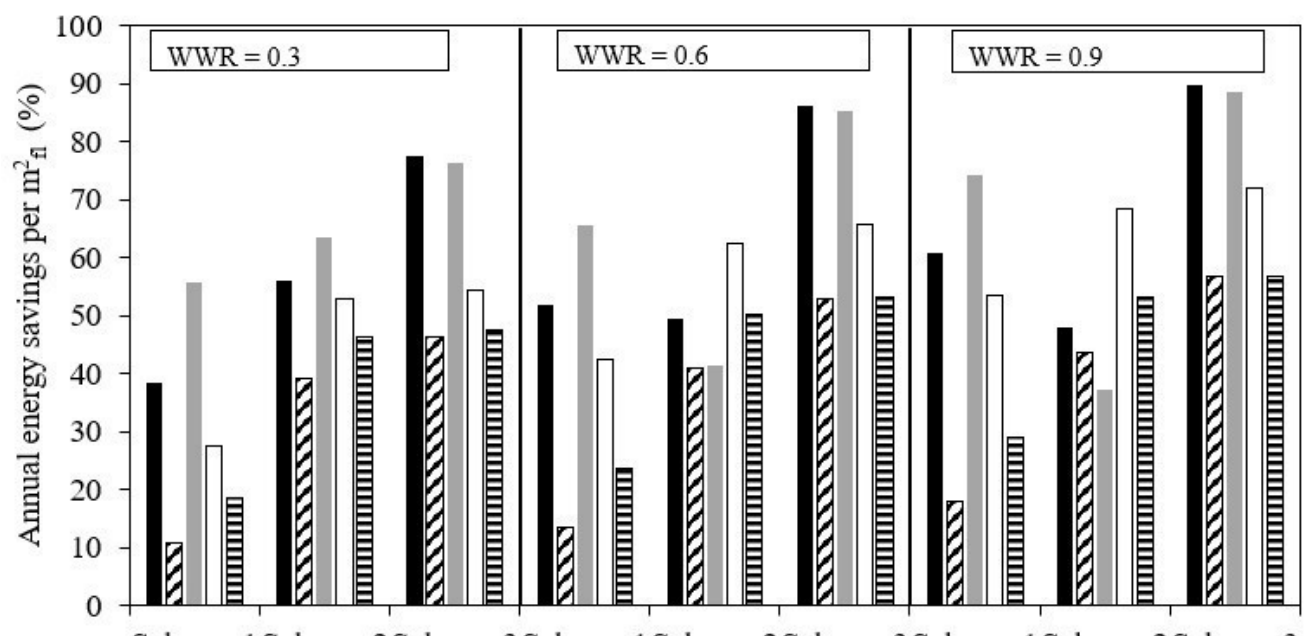

- $\mathrm{W}=3, \mathrm{D}=3$ [ $\mathrm{W}=3, \mathrm{D}=9$ $\mathrm{W}=9, \mathrm{D}=3$ $\square \mathrm{W}=9, \mathrm{D}=9$ $\mathrm{EW}=15, \mathrm{D}=15$

Scheme 1 Scheme 2 Scheme 3 Scheme 1 Scheme 2 Scheme 3 Scheme 1 Scheme 2 Scheme 3

Lighting schemes

Figure 10: Annual energy savings from daylighting integrated with task lighting.

\section{Acknowledgements}

The authors extend their sincere gratitude to the Joint Graduate School of Energy and Environment (JGSEE) at King Mongkut's University of Technology Thonburi for funding this research.

\section{References}

[1] Tagliabue, L. C., Buzzetti, M. and Arosio, B. 2012. Energy Saving Through The Sun: Analysis of Visual Comfort and Energy Consumption in Office Space. Energy Procedia. 30: 693-703.

[2] Nielsen, M. V., Svendsen, S. and Jensen, L. B. 2011. Quantifying the Potential of Automated Dynamic Solar Shading in Office Buildings Through Integrated Simulations of Energy and Daylight. Solar Energy. 85: 757-768.

[3] Oh, M. H., Lee, K. H. and Yoon, J. H. 2012. Automated Control Strategies of Inside Slat-Type Blind Considering Visual Comfort and Building Energy Performance. Energy And Buildings. 55: 728-737.

[4] Ghosh, A. and Neogi S. 2018. Effect of Fenestration Geometrical Factors on Building Energy Consumption And Performance Evaluation of a New External Solar Shading Device in Warm And Humid Climatic Condition. Solar Energy. 169: 94-104.

[5] Yao, J. 2014. An Investigation into the Impact of Movable Solar Shades on Energy. Building and Environment. 71: 24-32.

[6] Aries, M. B. C., Veitch, J. A. and Newsham, G. R. 2007. Physical and Psychological Discomfort in the Office Environment. Symposium of the Dutch Light and Health Research Foundation. 45-50.

[7] Chaiwiwatworakul, P., Mettanant, V. and Fathoni, A. M. 2016. Energy Analysis of the Daylighting from a Double-Pane Glazed Window with Enclosed Horizontal Slats in the Tropics. Energy and Buildings. 128: 413-430.

[8] Chaiwiwatworakul, P., Chirarattananon, S. and Rakkwamsuk, P. 2009. Application of Automated Blind for Daylighting in Tropical Region,” Energy Conversion And Management. 50: 2927-2943.

[9] Datta. G. 2001. Effect of Fixed Horizontal Louver Shading Devices on Thermal Performance of Building By TRNSYS Simulation. Renewable Energy. 23(3-4): 497-507.

[10] Ingabo, S. N., Chaiwiwatworakul, P. and Mettanant, V. 2020. Impact of External Horizontal Shading Slats on Indoor Visual Comfort in Tropical Climate. Naresuan University Journal of Science and Technology. 28(1): 23-37.

[11] Atzeri, A., Cappelletti, F. and Gasparella, A., 2014. Internal Versus External Shading Devices Performance in Office Buildings. Energy Procedia. 45: 463-472.

[12] Alzoubi, H. H. and Al-Zoubi. A. H. 2010. Assessment of Building Façade Performance in Terms of Daylighting and the Associated Energy Consumption in Architectural Spaces: Vertical and Horizontal Shading Devices for Southern Exposure Facades. Energy Conversion and Management. 51(8): 1592-1599.

[13] Tzempelikos, A. and Athienitis, A. K. 2007. The Impact of Shading Design and Control on Building Cooling and Lighting Demand. Solar Energy. 81(3), 369-382.

[14] Kralikova, R., Andrejiova, M. and Wessely, E. 2015. Energy Saving Techniques and Strategies for Illumination in Industry. Procedia Engineering, 100: 187-195.

[15] Veitch, J. A., Newsham, G. R., Boyce, P. R. and Jones, C. C. 2008. Lighting Appraisal, Well-being, and Performance in Open-Plan Offices: A Linked Mechanisms Approach. Lighting Research and Technology. 40(2), 133-151.

[16] Newsham, G. R., Arsenault, C. D., Veitch, J. A., Tasco, A. M. and Duval, C. L. 2005. Task Lighting Effects on Office Worker Satisfaction and Performance, and Energy Efficiency. Leukos. 1(4) 7-26.

[17] Jones C. C. and Gordon. K. L. 2004. Efficient Lighting Design and Office Worker Productivity. Proceedings of the 2004 ACEEE Summer Study on Energy Efficiency in Buildings. 22-27.

[18] Ingabo, S. N., Chirarattananon, S. and Chaiwiwatworakul, P. 2021. Application of External Horizontal Shading Slats for Daylighting Through North-Facing Windows. Science, Engineering and Health Studies. 15: 21040002.

[19] Chaiwiwatworakul, P., Chirarattananon, S. and Matuampunwong, D. 2012. Energy Saving Potential from Daylighting Through External Multiple-Slat Shaded Window in the Tropics. International Journal of Renewable Energy Research. 2(3): 376-383.

[20] V. D. Hien and S. Chirarattananon. 2009. “An Experimental Study of a Façade Mounted Light Pipe," Lighting Research and Technology. 41(2): 123-142.

[21] Chirarattananon, S. and Hien. V. D. 2011. Thermal Performance and Cost Effectiveness of Massive Walls Under Thai Climate. Energy and Buildings. 43(7) 1655-1662. 
Simeon Nyambaka Ingabo and Pipat Chaiwiwatworakul/JEST-Joumal of Energy and Safety Technology. vol. 4, no.2 (2021): 1-12

[22] Hien, V. D. and Chirarattananon, S. 2005. Triangular Subdivision for the Computation of Form Factors. Leukos.5(2): 41-59.

[23] Harrold, R. and Mennie, D. 2003. IESNA lighting ready reference: A compendium of materials from the IESNA, 9th ed., New York: Illuminating Engineering Society of North America.

[24] Nabil, A. and Mardaljevic, J. 2006. Useful Daylight Illuminance: A Replacement for Daylight Factors. Energy and Buildings. 38 : 905-913. 